\title{
ПРОГНОЗИРОВАНИЕ ДИНАМИКИ НАЛОГОВОЙ БАЗЫ ПО НАЛОГУ НА ИМУЩЕСТВО ОРГАНИЗАЦИЙ
}

\begin{abstract}
АНнотАЦия. Статья посвящена анализу налоговых поступлений в бюджеты субъектов Российской Федерации и прогнозированию налоговых поступлений на заданный временной период с помощью эконометрических методов. Актуальность работы обусловлена необходимостью развития современных подходов в области бюджетно-налогового прогнозирования. В статье особое внимание уделяется налогу на имущество организаций, а именно исследуется зависимость налоговой базы по налогу на имущество организаций от факторов, влияющих на ее формирование. В качестве эмпирической базы исследования использована статистическая налоговая отчетность в разрезе субъектов Российской Федерации за 2013 г. и базы данных Федеральной службы государственной статистики. На основе данных по 52 субъектам Российской Федерации построены регрессионные модели зависимости налоговой базы по налогу на имущество организаций, как в разрезе субъектов Российской Федерации, так и отдельно на примере Иркутской области. Полученные уравнения позволяют сделать вывод о том, как изменятся налоговые поступления в связи с изменением факторных показателей, и в дальнейшем спрогнозировать налоговые поступления на заданный временной период.
\end{abstract}

кЛючЕВЫЕ словА. Налог на имущество организаций; налоговая база; факторы; уравнение зависимости; прогнозирование.

ИНФОРМАЦИЯ О СТАТЬЕ. Дата поступления 19 апреля 2017 г.; дата принятия к печати 6 мая 2017 г.; дата онлайн-размещения 19 июня 2017 г.

P. G. Sorokina

Baikal State University, Irkutsk, Russian Federation

\section{FORECASTING OF TAX BASE DYNAMICS FOR CORPORATE PROPERTY TAX}

ABSTRACT. The article is devoted to analysis of tax revenues to budgets of the subjects of the Russian Federation and forecasting of tax revenues over the predetermined time period through use of econometric methods. The topicality of the work is determined by necessity of developing modern approaches in the field of the budget-tax forecasting. The article pays a special attention to the corporate property tax, namely, it examines dependence of the taxation base in the corporate property tax on the factors influencing its formation. As an empiric investigation base, it uses statistic tax reporting in terms of the Russian Federation subjects during the year of 2013 and the database of the Federal State Statistics Service. On the basis of data from 52 Russian Federation subjects, the article builds regression models of dependence of the taxation base in the corporate property tax both in terms of the Russian Federation subjects and separately in terms of Irkutsk Oblast. The equations obtained allow to draw a conclusion of how the tax revenues will change in connection with changes of the factor indicators and to forecast in future the tax revenues over the predetermined time period.

KEYWORDS. Property tax; taxation base; factors; equation of dependence; forecasting. ARTICLE INFO. Received April 19, 2017; accepted May 6, 2017; available online June 19, 2017.

(C) П. Г. Сорокина, 2017

\section{Baikal Research Journal}


Налоговая система Российской Федерации играет важную роль в развитии экономических отношений и обеспечении финансово-экономической стабильности в стране. Совершенствование налоговой системы требует современных продвижений в областях бюджетно-налогового прогнозирования и планирования. Под прогнозированием понимается взгляд в будущее, оценка возможных путей развития, последствий тех или иных решений. Планирование трактуется как разработка последовательности действий, позволяющих достигнуть желаемого результата. В налогообложении эти два понятия тесно связаны между собой: очевидно, что планирование предполагает предварительное прогнозирование экономической ситуации. Целью налогового планирования, как на федеральном, так и на региональном уровне, является оценка соотношения налогового потенциала $[1$, с. 350] и фактических поступлений налогов и сборов для определения объемов экономически обоснованных поступлений в бюджетную систему в планируемом периоде.

К сожалению, отечественный опыт в области формирования налоговых прогнозов и планов невелик. Только в XXI в. в отечественной литературе появились разделы, так или иначе освещающие теоретические вопросы налогового планирования. В силу новизны проблемы авторы по разному трактуют содержание подходов и методов прогнозирования и планирования, неоднозначна их классификация, отсутствует сравнительная характеристика подходов по определенному набору признаков. В работе А. С. Кокина и А. В. Едронова [2] анализируются современные теоретические прогнозные подходы применительно к налоговым доходам консолидированных бюджетов субъектов Российской Федерации. Авторы, на основе обобщения взглядов современных отечественных ученых, выделяют следующие подходы к налоговому прогнозированию:

- экстраполяционный - распространение установленных в прошлом тенденций на прогнозируемый период;

- детерминированный - определение плановых значений в виде уравнения зависимости между результативным показателем и макроэкономическими факторами;

- эконометрический - прогнозирование на основе системы регрессионных уравнений;

- экспертный - предположение специалиста об изменении того или иного элемента налогообложения на основе большого опыта налогового планирования.

В статье проведена сравнительная характеристика перечисленных подходов, которую можно рассматривать как предпосылку анализа отечественного опыта планирования налоговых поступлений в субъектах Российской Федерации.

В работе В. В. Доржиевой и Е. Ц. Чимитдоржиевой [3] проведен анализ налоговых поступлений в консолидированные бюджеты субъектов Федерации Сибирского Федерального округа. Отмечено, что поступления налога на имущество организаций являются одним из основных источников доходов региональных бюджетов. Авторами актуализируется проблема прогнозирования бюджетов субъектов Федерации Сибирского федерального округа.

Прогнозирование налоговых поступлений, как было отмечено выше, может быть сведено к моделированию зависимости динамики базы налогообложения от различных макро- и микроэкономических показателей. В работе [4] при прогнозировании и планировании поступлений доходов от имущественного налога выделяются следующие подходы:

- анализ на основе методов обработки временных рядов;

- оценка зависимости от возможных изменений показателей социально-экономического положения в регионах Российской Федерации;

- использование имитационного моделирования.

\section{Baikal Research Journal}


Отметим, что в странах с устойчивой налоговой системой планирование налоговых доходов бюджетов часто основывается на экономических прогнозах с широким использованием математического инструментария. В данной работе используется второй подход, который относится к эконометрическому методу прогнозирования.

Прогнозирование налоговых доходов имеет особое значение для бюджетов субъектов федерации и местных бюджетов, и напрямую связано с возможностью развития регионов на основе реализации собственного потенциала, в том числе и налогового [5]. Существенное влияние на налоговый потенциал региональных и местных бюджетов оказывают имущественное налоги, в том числе налог на имущество организаций.

В связи с этим в работе исследуется зависимость налоговой базы по налогу на имущество организаций в разрезе субъектов Российской Федерации от факторов, потенциально влияющих на ее формирование. Изменчивость динамики налоговой базы является результатом воздействия на него целого ряда взаимосвязанных и взаимозависимых социально-экономических показателей. Возникает «соблазн» включить в исследование все факторы, какие только можно, в надежде на то, что некоторые из них окажутся значимыми. Однако согласно теории регрессионного анализа необходимо использовать, по крайней мере, от семи до десяти наблюдений на одну переменную, в противном случае полученная модель, скорее всего, окажется непригодной для дальнейшего изучения. На основании этого в работе предварительно было экспертно отобрано семь факторов (переменных), так как общее количество наблюдений равно 52. Опишем проведенные этапы исследования.

Обозначим через $Y$ зависимую (результирующую) переменную - налоговую базу субъекта Российской Федерации. В качестве независимых факторов, от которых, предположительно, зависит размер налоговой базы, были выбраны [6]:

$x_{1}$ - плотность населения, чел./км²;

$x_{2}$ - степень износа, \%;

$x_{3}$ - инвестиции в основной капитал, млрд р.;

$x_{4}$ - валовой региональный продукт (ВРП) на душу населения, млрд р.;

$x_{5}$ - стоимость основных фондов, млрд р.;

$x_{6}$ - сальдированный финансовый результат деятельности организаций, млрд р.;

$x_{7}-$ количество льготников, чел.

С помощью формы статистической налоговой отчетности № 5 -НИО «Отчет о налоговой базе и структуре начислений по налогу на имущество организаций» в разрезе субъектов Российской Федерации за 2013 г. ${ }^{1}$ и базы данных Федеральной службы государственной статистики ${ }^{2}$ сформирована табл. 1 для 52 субъектов Российской Федерации.

Данные для исследования за 2013 г.

\begin{tabular}{|c|l|r|r|r|r|r|r|r|r|}
\hline № & \multicolumn{1}{|c|}{ Субъекты РФ } & \multicolumn{1}{|c|}{$Y$} & $x_{1}$ & \multicolumn{1}{c|}{$x_{2}$} & \multicolumn{1}{c|}{$x_{3}$} & $x_{4}$ & \multicolumn{1}{c|}{$x_{5}$} & \multicolumn{1}{c|}{$x_{6}$} & \multicolumn{1}{c|}{$x_{7}$} \\
\hline 1 & Белгородская область & 337513 & 56,8 & 43,3 & 129 & 369 & 1036 & 85 & 297 \\
\hline 2 & Воронежская область & 368231 & 44,6 & 43 & 217 & 263 & 1158 & 17 & 340 \\
\hline 3 & Костромская область & 76876 & 10,9 & 48,4 & 22 & 211 & 345 & 8 & 67 \\
\hline 4 & Курская область & 152227 & 37,3 & 47,9 & 72 & 243 & 607 & 42 & 330 \\
\hline 5 & Липецкая область & 280438 & 48,3 & 49,2 & 101 & 272 & 880 & 4 & 169 \\
\hline
\end{tabular}

${ }^{1}$ Федеральная налоговая служба Российской Федерации : офиц. сайт. URL: https://www.nalog.

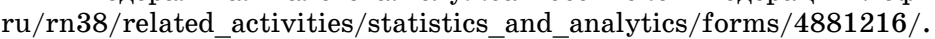

${ }^{2}$ Регионы России. Социально-экономические показатели. 2014 : стат. сб. / Росстат. М., 2014. 900 c. URL: http://www.gks.ru/wps/wcm/connect/rosstat_main/rosstat/ru/statistics/publications/ catalog/doc_1138623506156.

\section{Baikal Research Journal}


Окончание табл. 1

\begin{tabular}{|c|c|c|c|c|c|c|c|c|c|}
\hline № & Субъекты РФ & $Y$ & $x_{1}$ & $x_{2}$ & $x_{3}$ & $x_{4}$ & $x_{5}$ & $x_{6}$ & $x_{7}$ \\
\hline 6 & Московская область & 1830882 & 159,0 & 40,5 & 588 & 359 & 5539 & 209 & 394 \\
\hline 7 & Рязанская область & 205968 & 28,9 & 51 & 76 & 244 & 671 & 18 & 2233 \\
\hline 8 & Тверская область & 355957 & 15,8 & 41 & 81 & 225 & 1008 & -3 & 839 \\
\hline 9 & Тульская область & 249852 & 59,7 & 45,3 & 91 & 228 & 765 & 21 & 171 \\
\hline 10 & г. Москва & 4758385 & 4677,7 & 33,2 & 1413 & 981 & 26547 & 8 & 4899 \\
\hline 11 & Республика Карелия & 145305 & 3,5 & 43,4 & 34 & 281 & 485 & 9 & 871 \\
\hline 12 & Республика Коми & 704372 & 2,1 & 46,2 & 199 & 550 & 1938 & 85 & 1847 \\
\hline 13 & $\begin{array}{l}\text { Архангельская область без } \\
\text { АО }\end{array}$ & 325797 & 2,8 & 42,9 & 96 & 283 & 966 & 3 & 105 \\
\hline 14 & Вологодская область & 557073 & 8,3 & 43,1 & 75 & 290 & 1236 & 16 & 271 \\
\hline 15 & Калининградская область & 192167 & 63,1 & 34,7 & 69 & 288 & 583 & 13 & 371 \\
\hline 16 & Ленинградская область & 824318 & 20,9 & 32,4 & 254 & 386 & 2276 & 96 & 2425 \\
\hline 17 & Новгородская область & 139928 & 11,5 & 43,8 & 53 & 287 & 393 & -1 & 379 \\
\hline 18 & г. Санкт-Петербург & 1523857 & 3583,7 & 36,8 & 475 & 490 & 4349 & 499 & 3524 \\
\hline 19 & Ростовская область & 713615 & 42,1 & 42,2 & 254 & 216 & 2004 & 47 & 1330 \\
\hline 20 & Республика Дагестан & 159005 & 58,6 & 42,1 & 179 & 153 & 986 & -6 & 55 \\
\hline 21 & Республика Ингушетия & 14833 & 121,9 & 50,5 & 19 & 102 & 66 & -1 & 9 \\
\hline 22 & $\begin{array}{l}\text { Кабардино-Балкарская } \\
\text { Республика }\end{array}$ & 44748 & 68,9 & 33,8 & 22 & 129 & 217 & -2 & 62 \\
\hline 23 & $\begin{array}{l}\text { Респ. Северная Осетия - } \\
\text { Алания }\end{array}$ & 50938 & 88,4 & 47,3 & 29 & 168 & 197 & $\begin{array}{llll}-1 & & & \\
\end{array}$ & 17 \\
\hline 24 & Чеченская Республика & 47610 & 84,7 & 50,5 & 45 & 92 & 404 & -11 & 917 \\
\hline 25 & Ставропольский край & 344786 & 42,2 & 50 & 131 & 172 & 1244 & 13 & 315 \\
\hline 26 & Республика Башкортостан & 568823 & 28,4 & 52,2 & 266 & 286 & 2106 & 149 & 346 \\
\hline 27 & Республика Татарстан & 1039844 & 56,3 & 43,4 & 526 & 405 & 3343 & 219 & 777 \\
\hline 28 & Удмуртская Республика & 231751 & 36,1 & 62,3 & 83 & 267 & 870 & 47 & 141 \\
\hline 29 & Чувашская Республика & 157522 & 67,8 & 53,5 & 60 & 180 & 654 & 2 & 424 \\
\hline 30 & Кировская область & 128715 & 11,0 & 51,9 & 59 & 170 & 683 & 11 & 367 \\
\hline 31 & Нижегородская область & 594153 & 42,9 & 49,7 & 281 & 282 & 2138 & 80 & 1058 \\
\hline 32 & Оренбургская область & 389850 & 16,3 & 55,9 & 153 & 356 & 1597 & 100 & 3634 \\
\hline 33 & Пензенская область & 148798 & 31,6 & 51,3 & 82 & 198 & 720 & 1 & 83 \\
\hline 34 & Самарская область & 678897 & 60,0 & 53,5 & 270 & 326 & 2343 & 151 & 405 \\
\hline 35 & Саратовская область & 405844 & 24,7 & 53,5 & 126 & 210 & 1456 & 16 & 287 \\
\hline 36 & Курганская область & 114151 & 12,4 & 58,6 & 33 & 190 & 617 & 2 & 51 \\
\hline 37 & Свердловская область & 1089895 & 22,2 & 57,8 & 353 & 363 & 3949 & 103 & 5919 \\
\hline 38 & Тюменская область без АО & 399331 & 8,6 & 46,7 & 245 & 605 & 1545 & 159 & 1762 \\
\hline 39 & Челябинская область & 661091 & 39,4 & 47,5 & 215 & 253 & 2161 & -34 & 263 \\
\hline 40 & Республика Алтай & 33717 & 2,3 & 22,4 & 12 & 158 & 86 & 3 & 14 \\
\hline 41 & Республика Бурятия & 175798 & 2,8 & 29,8 & 42 & 182 & 521 & 9 & 65 \\
\hline 42 & Республика Хакасия & 101522 & 8,7 & 31,3 & 32 & 266 & 341 & 5 & 1000 \\
\hline 43 & Алтайский край & 228774 & 14,3 & 41,1 & 95 & 174 & 870 & 18 & 106 \\
\hline 44 & Забайкальский край & 233705 & 2,5 & 35 & 57 & 210 & 754 & -3 & 38 \\
\hline 45 & Иркутская область & 735262 & 3,1 & 40,7 & 200 & 333 & 2077 & 139 & 3651 \\
\hline 46 & Новосибирская область & 500575 & 15,2 & 41,3 & 184 & 301 & 1481 & 30 & 168 \\
\hline 47 & Томская область & 289317 & 3,4 & 50,6 & 103 & 377 & 987 & 34 & 1570 \\
\hline 48 & Республика Саха (Якутия) & 544045 & 0,3 & 35 & 194 & 597 & 1336 & 48 & 197 \\
\hline 49 & Приморский край & 605230 & 11,8 & 27,1 & 123 & 297 & 2612 & 15 & 1734 \\
\hline 50 & Хабаровский край & 626245 & 1,7 & 28,3 & 150 & 371 & 1353 & 5 & 129 \\
\hline 51 & Амурская область & 369382 & 2,3 & 26,9 & 102 & 259 & 816 & 6 & 323 \\
\hline 52 & Сахалинская область & 167399 & 5,7 & 31,9 & 176 & 1365 & 1441 & 22 & 903 \\
\hline
\end{tabular}

\section{Baikal Research Journal}


Для того чтобы создать регрессионную модель влияния факторов на размер налоговой базы по субъектам Российской Федерации необходимо построить матрицу парных коэффициентов корреляции [7] и пошаговым методом отобрать значимые факторы для последующего моделирования (табл. 2).

Таблица 2

Матрица парных коэффищиентов коррелящии

\begin{tabular}{|c|c|c|c|c|c|c|c|c|}
\cline { 2 - 9 } \multicolumn{1}{c|}{} & $Y$ & $x_{1}$ & $x_{2}$ & $x_{3}$ & $x_{4}$ & $x_{5}$ & $x_{6}$ & $x_{7}$ \\
\hline$Y$ & 1,00 & & & & & & & \\
\hline$x_{1}$ & 0,82 & 1,00 & & & & & & \\
\hline$x_{2}$ & $-0,17$ & $-0,18$ & 1,00 & & & & & \\
\hline$x_{3}$ & 0,97 & 0,78 & $-0,12$ & 1,00 & & & & \\
\hline$x_{4}$ & 0,51 & 0,43 & $-0,25$ & 0,55 & 1,00 & & & \\
\hline$x_{5}$ & 0,97 & 0,83 & $-0,15$ & 0,94 & 0,52 & 1,00 & & \\
\hline$x_{6}$ & 0,34 & 0,41 & 0,04 & 0,40 & 0,25 & 0,16 & 1,00 & \\
\hline$x_{7}$ & 0,59 & 0,51 & 0,04 & 0,57 & 0,41 & 0,55 & 0,42 & 1,00 \\
\hline
\end{tabular}

Анализ матрицы коэффициентов парной корреляции показывает, что зависимая переменная $Y$ (налоговая база) имеет тесную связь с факторами $x_{1}, x_{3}$ и $x_{5}$. Однако, многие факторы тесно связаны между собой ( $x_{3}$ и $x_{1}, x_{5}$ и $x_{1}, x_{5}$ и $x_{3}$ ), что свидетельствует о наличии мультиколлинеарности.

В результате пошагового отбора факторов уравнение регрессии выглядит следующим образом:

$$
Y=42206,92+1,1 x_{3}+0,12 x_{5}+0,8 x_{6} .
$$

Данная модель по $F$-критерию Фишера является пригодной для дальнейшего исследования. Факторы $x_{6}, x_{5}$ и $x_{6}$ являются статистически значимыми с вероятностью $95 \%$. Экономический смысл коэффициентов уравнения следующий.

При увеличении инвестиций в основной капитал на 1 млрд р. налоговая база вырастет на 1,1 млрд р. При повышении стоимости основных фондов на 1 млрд р. налоговая база вырастет на 0,12 млрд р. При увеличение сальдированного финансового результата деятельности организации на 1 млрд р. налоговая база вырастет на 0,8 млрд $\mathrm{p}$.

Найдем коэффициент эластичности. Напомним, что коэффициент эластичности показывает, на сколько процентов изменится значение исследуемой величины при увеличении соответствующего фактора на $1 \%$. Налоговая база возрастет на $0,038 \%$ при увеличении инвестиций в основной капитал на $1 \%$. При повышении стоимости основных фондов на $1 \%$ рост налоговой базы составит 0,044 \%. Увеличение сальдированного финансового результата деятельности организаций на $1 \%$ приведет к повышению налоговой базы на 0,008 \% .

Коэффициент детерминации $R^{2}=0,97$ в модели регрессии показывает, что вариация налоговой базы субъекта Российской Федерации на 97 \% объясняется изменчивостью инвестиций в основной капитал, стоимости основных фондов и сальдированного финансового результата деятельности организаций. При этом оставшиеся 3 \% приходятся на неучтенные в модели факторы.

Построим аналогичную модель зависимости налоговой базы Иркутской области $Y$ от влияющих на ее формирование факторов. При построении модели использовалась база данных показателей муниципальных образований Иркутской области за 2013 г. $^{3}$, из которой для дальнейшего исследования отобрано 31 муни-

${ }^{3}$ Федеральная служба государственной статистики : офиц. сайт. URL: http://www.gks.ru/wps/ $\mathrm{wcm} /$ connect/rosstat_main/rosstat/ru/statistics/publications/catalog/doc_1138623506156.

\section{Baikal Research Journal}


ципальное образование Иркутской области. В качестве независимых переменных рассмотрим факторы, которые в предыдущей модели оказались статистически значимыми:

$x_{1}$ - инвестиции в основной капитал, млрд р.;

$x_{2}$ - стоимость основных фондов, млрд р.;

$x_{3}$ - сальдированный финансовый результат деятельности организаций, млрд $\mathrm{p}$.

Для оценки взаимосвязи переменных обратимся к табл. 3.

Таблица 3

Матрица парных коэффициентов корреляции

\begin{tabular}{|c|c|c|c|c|}
\cline { 2 - 5 } \multicolumn{1}{c|}{} & $Y$ & $x_{1}$ & $x_{2}$ & $x_{3}$ \\
\hline$Y$ & 1,00 & & & \\
\hline$x_{1}$ & 0,09 & 1,00 & & \\
\hline$x_{2}$ & 0,98 & 0,07 & 1,00 & \\
\hline$x_{3}$ & 0,91 & 0,06 & 0,96 & 1,00 \\
\hline
\end{tabular}

Из матрицы видно, что с зависимой переменной $Y$ тесно связаны переменные $x_{2}$ и $x_{3}$. С переменной $x_{1}$ налоговая база Иркутской области связана слабо. Отметим, что переменные $x_{2}$ и $x_{3}$ между собой тесно связаны, что свидетельствует о наличии мультиколлинеарности.

После исключения факторов, не оказывающих существенного влияния на налоговую базу, уравнение регрессии принимает вид:

$$
Y=-3730,649+0,005 x_{2},
$$

которое является статистически значимым по $F$-критерию Фишера. Отметим, что наибольшее влияние на налоговую базу Иркутской области оказывает только один из перечисленных выше факторов - стоимость основных фондов. Таким образом, при увеличении стоимости основных фондов на 1 млрд р. налоговая база Иркутской области вырастет на 0,005 млрд р. При увеличении стоимости основных фондов на $1 \%$ налоговая база увеличится на $0,1 \%$.

Коэффициент детерминации в модели $R^{2}=0,96$ показывает, что вариация налоговой базы Иркутской области на 96 \% объясняется изменчивостью стоимостью основных фондов. При этом оставшиеся 4 \% приходятся на неучтенные в модели факторы.

В результате исследования в работе построены регрессионные модели зависимости налоговой базы от факторов, влияющих на ее формирование, как в разрезе субъектов Российской Федерации, так и на примере Иркутской области. Полученные уравнения позволяют сделать вывод о том, как изменятся налоговые поступления в связи с изменением факторных показателей. Модели отличаются друг от друга количеством и составом факторов. Так в уравнение зависимости налоговой базы Иркутской области факторы инвестиции в основной капитал и сальдированный финансовый результат деятельности организаций статистически незначимы. В работе [8] приводятся причины невысокой инвестиционной активности в Иркутской области и сформулированы предложения по развитию инвестиционных процессов в области. Одной из основных причин низких инвестиций в основной капитал в Иркутской области является преобладание в регионе предприятий, производящих экспортную продукцию. Это означает, что инвесторы ориентированы на внешние сырьевые рынки, а не на внутренний спрос. Сказывается потребительское отношение крупнейших предприятий региона к территории своей деятельности. Крупнейшие экспортеры встроены в транснациональные корпорации, собственники которых проживают за пределами области и не настроены на развитие региона. Отметим также, что в Иркутской области, в отличие от большинства

\section{Baikal Research Journal}


регионов, собственные источники преобладают над привлеченными. Ориентируясь, в основном, на собственные финансовые возможности, компании региона сокращают свой инвестиционный потенциал. Сальдированный финансовый результат определяется как разница между суммой прибыли прибыльных организаций и суммой убытков убыточных организаций. Отметим, что данный показатель у половины муниципальных образований в Иркутской области отрицателен или равен нулю, а это означает, что сумма убытков убыточных организаций больше или равна сумме прибыли прибыльных организаций и, следовательно, имеет место убыточность.

Налог на имущество организаций занимает центральное место в системе имущественного налогообложения в России по сумме налоговых поступлений и обеспечивает в среднем 11 \% собственных доходов региональных бюджетов. В соответствии с положениями Основных направлений налоговой политики до 2016 г. продолжение налоговой реформы связано с переходом к налогообложению имущества организаций исходя из кадастровой стоимости объектов недвижимости [9, с. 363]. К таким объектам отнесены административно-деловые центры, торговые и офисные помещения, а также имущество иностранных организаций, не имеющих представительства в Российской Федерации. Налоговая ставка для субъектов Российской Федерации не может превышать $2 \%$, начиная с 2016 г.

Результаты, полученные в работе позволяют:

- исследовать зависимость изменения налогооблагаемой базы в регионах, которые ввели кадастровую оценку, от различных факторов;

- сравнить полученные результаты с уравнением зависимости налогооблагаемой базы в регионах, которые не ввели кадастровую оценку; по возможности, выявить общие тенденции;

- спрогнозировать налоговую базу по налогу на имущество организаций субъектов Российской Федерации на заданный временной период.

\section{Список использованной литературы}

1. Энциклопедия теоретических основ налогообложения / под ред. И. А. Майбурова, Ю. Б. Иванова. - М. : Юнити-Дана, 2016. - 503 с.

2. Кокин А. С. Сравнительная характеристика подходов к планированию налоговых доходов бюджетов субъектов российской Федерации / А. С. Кокин, А. В. Едронов // Финансы и кредит. - 2009. - № 47 (383). - С. 2-11.

3. Доржиева В. В. Дифференциация регионов и проблемы асимметрии налоговых поступлений в консолидированные бюджеты субъектов Федерации Сибирского федерального округа / В. В. Доржиева, Е. Ц. Чимитдоржиева // Экономический анализ: теория и практика. - 2012. - № 36. - С. 30-44.

4. Анимица П. Е. Применение методов прогнозирования в целях диагностики имущественных налогов / П. Е. Анимица // Проблемы прогнозирования и сценарного моделирования социально-экономического развития территориальных систем : сб. ст. 1-й Науч. шк. молодых ученых. - Екатеринбург : Изд-во Ин-та экономики Урал. отд-ния РАН, 2012. - C. $4-10$.

5. Киреенко А. П. Проявления региональной налоговой политики в условиях российского бюджетного федерализма / А. П. Киреенко, Е. Н. Орлова // Регион: Экономика и Социология. - 2014. - № 1 (81). - С. 193-217.

6. Лермонтов Ю. М. Показатели, оказывающие влияние на поступление налога на прибыль в бюджетную систему Российской Федерации / Ю. М. Лермонтов // Налоговый вестник. - 2004. - № 6. - С. 14-17.

7. Эконометрика : учебник / под ред. И. И. Елисеевой. - 2-е изд., перераб. и доп. М. : Финансы и статистика, 2007. - 576 с.

8. Федотов Д. Ю. Проблемы развития инвестиционной деятельности в экспортоориентированном регионе (на примере Иркутской области) / Д. Ю. Федотов // Известия Уральского государственного экономического университета. - 2014. - № 6 (56). - С. 70-80.

\section{Baikal Research Journal}


9. Фискальный федерализм. Проблемы и перспективы развития : монография для магистров / под. ред. И.А. Майбурова, Ю.Б. Иванова. - М. : Юнити-Дана, 2015. — 415 с. — (Magister).

\section{References}

1. Maiburov I. A. Ivanov Yu. B. (eds). Entsiklopediya teoreticheskikh osnov nalogooblozheniya [Encyclopedia of Theoretical Basics of Taxation]. Moscow, Yuniti-Dana Publ., 2016. 503 p.

2. Kokin A. S., Edronov A. V. Comparative characteristic of approaches to planning tax budget revenues of the Russian Federation subjects. Finansy $i$ kredit $=$ Finance and Credit, 2009, no. 47 (383), pp. 2-11. (In Russian).

3. Dorzhiyeva V. V., Chimitdorzhiyeva E. Ts. Differentiation of regions and problems of asymmetry tax revenues into consolidated budgets of the Federation's subjects of the Siberian Federal District. Ekonomicheskii analiz: teoriya $i$ praktika = Economic Analysis: Theory and Practice, 2012, no. 36, pp. 30-44. (In Russian).

4. Animitsa P. E. Using methods of forecasting with the purpose of diagnosing property taxes. Problemy prognozirovaniya i stsenarnogo modelirovaniya sotsial'no-ekonomicheskogo razvitiya territorial'nykh sistem [Problems of forecasting and scenery modelling of socio-economic development of territorial systems]. Yeketerinburg, Institute of Economic, Ural Branch of Russian Academy of Sciences Publ., 2012, pp. 4-10. (In Russian).

5. Kireyenko A. P., Orlova E. N. Regional fiscal policy in the context of Russian fiscal federalism. Region: Ekonomika $i$ Sotsiologiya = Region: Economics and Sociology, 2014, no. 1 (81), pp. 193-127. (In Russian).

6. Lermontov Yu. M. Indictors that influence profit tax revenues in budget system of the Russian Federation. Nalogovyi vestnik = Taxation Bulletin, 2004, no. 6, pp. 14-17. (In Russian).

7. Eliseyeva I. I. (ed.). Ekonometrika [Econometrics]. $2^{\text {nd }}$ ed. Moscow, Finansy i statistika Publ., 2012. 576 p.

8. Fedotov D. Yu. Problems of expanding investment activity in the export-oriented region (in terms of Irkutsk Oblast). Izvestiya Ural'skogo gosudarstvennogo ekonomicheskogo universiteta = Journal of Ural State University of Economics, 2014, no. 6 (56), pp. 70-80. (In Russian).

9. Maiburov I. A., Ivanov Yu. B. (eds). Fiskal'nyi federalizm. Problemy i perspektivy razvitiya [Fiscal Federalism. Problems and Prospects of Development]. Moscow, Yuniti-Dana Publ., 2015. 415 p.

\section{Информация об авторе}

Сорокина Полина Геннадьевна - аспирант, кафедра налогов и таможенного дела, Байкальский государственный университет, 664003, г. Иркутск, ул. Ленина, 11; e-mail: ermolaeva_polina@mail.ru.

\section{Author}

Polina G. Sorokina - PhD Student, Chair of Taxation and Customs, Baikal State University, 11 Lenin St., 664003, Irkutsk, Russian Federation; e-mail: ermolaeva_polina@mail.ru.

\section{Библиографическое описание статьи}

Сорокина П. Г. Прогнозирование динамики налоговой базы по налогу на имущество организаций / П. Г. Сорокина // Baikal Research Journal. — 2017. — T. 8, № 2. — DOI: 10.17150/2411-6262.2017.8(2).16.

\section{Reference to article}

Sorokina P. G. Forecasting of tax base dynamics for corporate property tax. Baikal Research Journal, 2017, vol. 8, no. 2. DOI: 10.17150/2411-6262.2017.8(2).16. (In Russian).

\section{Baikal Research Journal}

